\title{
A public health threat in Hungary: obesity, 2013
}

\author{
Imre Rurik ${ }^{1 *}$, Péter Torzsa ${ }^{3}$, Judit Szidor ${ }^{1}$, Csaba Móczár ${ }^{4}$, Gabriella Iski ${ }^{1}$, Éva Albók', Tímea Ungvári ${ }^{1}$, \\ Zoltán Jancsó ${ }^{1}$ and János Sándor ${ }^{2}$
}

\begin{abstract}
Background: In Hungary, the last wide-range evaluation about nutritional status of the population was completed in 1988. Since then, only limited data were available. Our aim was to collect, analyze and present updated prevalence data.

Methods: Anthropometric, educational and morbidity data of persons above $18 \mathrm{y}$ were registered in all geographical regions of Hungary, at primary care encounters and within community settings.

Results: Data (BMI, waist circumference, educational level) of 40,331 individuals (16,544 men, 23,787 women) were analyzed. Overall prevalence for overweight was $40.4 \%$ among men, $31.3 \%$ among women, while for obesity $32.0 \%$ and $31.5 \%$, respectively. Abdominal obesity was $37.1 \%$ in males, $60.9 \%$ in females. Among men, the prevalence of overweight-obesity was: under $35 \mathrm{y}=32.5 \%-16.2 \%$, between 35-60 y=40.6\%-34.7\%, over $60 \mathrm{y}=44.3 \%-36.7 \%$. Among women, in the same age categories were: 17.8\%-13.8\%, 29.7\%-29.0\%, and 36.9\%-39.0\%. Data were presented according to age by decades as well. The highest odds ratio of overweight (OR: 1.079; 95\% Cl [1.026-1.135]) was registered by middle educational level, the lowest odds ratio of obesity (OR: 0.500; $95 \% \mathrm{Cl}$ [0.463-0.539]) by the highest educational level. The highest proportion of obese people lived in villages (35.4\%) and in Budapest (28.9\%). Distribution of overweighed persons were: Budapest (37.1\%), other cities (35.8\%), villages (33.8\%). Registered metabolic morbidities were strongly correlated with BMls and both were inversely related to the level of urbanization. Over the previous decades, there has been a shift in the distribution of population toward being overweight and moreover obese, it was most prominent among males, mainly in younger generation.
\end{abstract}

Conclusions: Evaluation covered $0.53 \%$ of the total population over $18 \mathrm{y}$ and could be very close to the proper national representativeness. The threat of obesity and related morbidities require higher public awareness and interventions.

Keywords: Hungary, Obesity, Overweight, Prevalence, Primary care, Public health

\section{Background}

Obesity, a worldwide pandemic, is well-known for the readers who are interested in metabolic diseases with high public health impact. While obesity is mainly a medical problem, its related metabolic, cardiovascular and other diseases have serious public health and other economic or social implications. Health care services provided for obese patients are usually more expensive, mainly for the complications related to this condition. The increasing ratio of overweight and obese people is visible in all health care settings and also in public places. It has been described as a world-wide trend, although there are differences between and within countries and populations $[1,2]$.

\footnotetext{
* Correspondence: Rurik.Imre@sph.unideb.hu

'Department of Family and Occupational Medicine, Faculty of Public Health, University of Debrecen, Móricz Zs. krt.22, 4032 Debrecen, Hungary Full list of author information is available at the end of the article
}

A similar trend was observed in previous Hungarian evaluations, although the issue and importance of obesity were realized later than in other countries $[3,4]$.

Measuring and registering anthropometric parameters is rarely obligatory at different levels of health care provision, let alone in the "healthy" population. Although measuring everyone in a society is impossible, finding and reaching the required representation is crucial. Studies and surveys in other countries have used quite different methods for the selection of participants and so have the Hungarian ones $[1,5]$. Representative selections can be based on geographical or domicile distribution; they may respect the age cohorts and educational levels. Planning and performing a large scale and, also, representative evaluation often involves compromises.

The first wide range Hungarian study was performed between 1985 and 1988. It was a professionally planned 
survey with wide geographical distribution, targeting the whole population of the country. Morbidities, anthropometric parameters, nutritional habits and living circumstances were registered. Data of 16,641 individuals (7,042 men and 9,599 women) were collected by trained staff of the National Institute of Food Hygiene and Nutrition [3]. The following means of BMI were found within the age group of men between 19-34 year $=24.2 \mathrm{~kg} / \mathrm{m}^{2}$, between $35-59$ year $=26.3 \mathrm{~kg} / \mathrm{m}^{2}$, between $60-74$ year $=26.7 \mathrm{~kg} / \mathrm{m}^{2}$ and above 75 year $=$ $25.8 \mathrm{~kg} / \mathrm{m}^{2}$. Due to the earlier retirement age of women, other groups were formed for them resulting these data: $19-34$ year $=23.3 \mathrm{~kg} / \mathrm{m}^{2}, 35-54$ year $=26.0 \mathrm{~kg} / \mathrm{m}^{2}, 55-74$ year $=28.1 \mathrm{~kg} / \mathrm{m}^{2}$ and above 75 year $=27.0 \mathrm{~kg} / \mathrm{m}^{2}$. Within all age groups, the prevalence of overweight was $41.6 \%$ for men and $32.1 \%$ for women, while obesity was recorded in $11.6 \%$ and $18.1 \%$ of men and women, respectively.

A similar but smaller professional study was conducted between 1992 and 1994 measuring altogether 2,568 people of different ages. Among the 1,164 men examined, the prevalence of overweight was $41.9 \%$, and that of obesity was $21.0 \%$. Overweight was recorded in $27.9 \%$, obesity in $21.1 \%$ of the 1,404 females who participated in the survey [4].

Ten years later, in a survey among incidentally involved primary care patients between 40-70 y of age, $45 \%$ prevalence of overweight and $32 \%$ of obesity was diagnosed, $3 \%$ of them with morbid obesity [6].

According to the WHO database, the prevalence of obesity was $26.2 \%$ among Hungarian males and $22.9 \%$ among females. Overweight was found $65.8 \%$ and $49.4 \%$ among males and females, respectively, increased by age, although the sources of data were not clearly described [1].

In 2009, a nationwide study targeted to select participants representatively, achieved only $35 \%$ response rate. Health workers measured the anthropometric parameters of 1,165 people. The means of BMI in the selected age groups of men were as follows: $18-34 \mathrm{y}=25.0 \mathrm{~kg} / \mathrm{m}^{2}$, $35-64 \mathrm{y}=28.4 \mathrm{~kg} / \mathrm{m}^{2}$ and over $65 \mathrm{y}=28.7 \mathrm{~kg} / \mathrm{m}^{2}$. The same data for women were $23.6 \mathrm{~kg} / \mathrm{m}^{2}, 28.1 \mathrm{~kg} / \mathrm{m}^{2}$ and $29.8 \mathrm{~kg} / \mathrm{m}^{2}$, respectively. Obesity was diagnosed in $26.2 \%$ of men and in $30.4 \%$ of women, while morbid obesity was presented in $3.1 \%$ and $2.6 \%$, respectively. Abdominal obesity was more prevalent among women than men (51.0\% vs. $33.2 \%)$ and its ratio increased parallel with age in both genders $[7,8]$.

At the same time, another survey was conducted via the internet in various regions of Hungary involving 27,746 responders who filled the questionnaires. Among males, according to the self-measured data, overweight was reported by $31.5 \%, 43.5 \%$ and $49.6 \%$ in the age groups of 18-34 y, 35-64 y and over $65 \mathrm{y}$, respectively, while these figures were $17.8 \%, 33.6 \%$ and $39 \%$ among females. Within the same age categories, obesity was measured at $14 \%$,
$30.8 \%$ and $26.4 \%$ among men and at $12.5 \%, 27.4 \%$ and $28.4 \%$ among women. Irrespectively of age, self-measured overweight was reported by $40.6 \%$ of men and $30.5 \%$ of women, obesity by $25.0 \%$ and $23.6 \%$ [9].

A specific professional group was selected for a survey in 2002. Among 18,763 policemen and 2,037 policewomen (20-55 year), the prevalence of obesity was $19.1 \%$ and that of overweight was $43.8 \%$. The distribution of waist circumference between $94-102 \mathrm{~cm}$ was $21.9 \%$, above $102 \mathrm{~cm}$ was $22.6 \%$. The ratio of obese officers increased with the age; it was $11.8 \%$ (between $20-25$ year) and as high as $29.3 \%$ (between $40-45$ year). Geographical differences were also recorded. Obesity was presented in $15.3 \%$ among policemen who served in the capital, and in $19.4 \%$ among those who were country-based [10].

Aim

Since reliable, updated data of the Hungarian population are lacking, our main goal was to fit this gap. Collecting and presenting new data and comparing them to figures of the last wide range survey of 25 years before was aimed. Without governmental support, we approached primary care providers.

\section{Methods}

Our study was conducted between September 2012 and April 2013, at primary care encounters and during community activities of primary health care staff including occupational health services as well, in all geographical regions in Hungary. Only non-institutionalized adults from 18 years of age were involved on a voluntary basis.

\section{Selection for subjects and criteria for exclusion}

The participating family physicians (GPs) were given a detailed written description of methods for anthropometric measurements and asked to recruit the first 200 persons (over 18 y) visiting their office or persons who were seen by their community activities. They were asked to fill a written or electronic data sheet with the figures below.

Only those patients were excluded whose conditions might have been influenced by morbidities with weight consequences (cancer, COPD, cystic fibrosis, renal failure, pregnant and lactating women, etc.). Exclusion was decided by the GP.

\section{Body height $[\mathrm{cm}]$}

Persons on barefoot, measured with approved stadiometer, when head positioned in Frankfort plane (an imaginary line from lower border of the eye orbit to the auditory meatus).

\section{Body weight [kg]}

Measured with a regularly calibrated weighing machine, in light clothing, fasting and with empty bladder, after defecation. 


\section{Waist circumference $[\mathrm{cm}]$}

Using a professional tape (measured horizontally, halfway between the lower margin of ribs and iliac crest. Umbilical level was inacceptable).

All data were expressed in round figures.

The presence or absence of metabolic disease (diabetes and/or hypertension) was also registered.

\section{Educational level}

The participants' highest achieved level of education: not completed the 8-year elementary school (under), completed only elementary school (primary), graduated in secondary school and/or skilled worker qualification (secondary), having university or college degree (higher).

The WHO-established BMI categories were used in our survey (underweight $<18.5 \mathrm{~kg} / \mathrm{m}^{2}$, normal $=18.5$ $24.9 \mathrm{~kg} / \mathrm{m}^{2}$, overweight $=25-29.9 \mathrm{~kg} / \mathrm{m}^{2}$, obese $>30 \mathrm{~kg} / \mathrm{m}^{2}$ ).

Regarding waist circumference, the upper limit of normal range was $94 \mathrm{~cm}$ for men and $80 \mathrm{~cm}$ for women, the "risky" range was between 94-102 and 88-94 cm respectively, and abdominal obesity was diagnosed above these values.

\section{Statistics}

Descriptive statistics were done. Proportions were calculated with 95\% confidence intervals. Univariate and multivariate logistic regression models were created to check the associations between the outcome and its influencing factors. Odds ratios were reported with their 95\% confidence intervals. Statistical analyses were performed in Stata 9.2.programme.

\section{Results}

Altogether, the data of 41,163 subjects were collected and 40,331 (16,544 men and 23,787 women) were analyzed, because of missing or incomplete records.

Coming from all parts of Hungary, the number of participating GPs was 244 , representing $3.5 \%$ of all primary care practices. The location and number of practices were as follows: Budapest, the capital of Hungary: 38, cities and towns: 99, and villages: 107 .

The Tables 1 and 2 present the most important data of prevalence and distribution of BMI and waist circumference in our recent study, compared with the same age categories of the survey in 1985-1988 [3]. Visible shift toward higher BMI groups can be observed in all categories.

Increase in waist circumference, already in the younger generation is visible among figures of the Table 3.

According to waist circumference, parameters of risk were identified among more men in rural than urban settings. In their fourth decade of life (30-39 year), the ratio of males at risk was much higher $(20.0 \%$ vs. $26.8 \%)$ in the rural population and in the fifth decade $(40-49 \mathrm{y})$ it was still higher $(31.5 \%$ vs. $36.4 \%)$. A similar trend was observed among rural women $(38.2 \%$ vs. $54.9 \%)$ in their forties and (63.8\% vs.75.5\%) above 70 (years of age).

Table 1 BMI

\begin{tabular}{|c|c|c|c|c|c|c|c|c|c|}
\hline & \multicolumn{5}{|c|}{ Men [\%] } & \multicolumn{4}{|c|}{ Women [\%] } \\
\hline & Age [y] & Underweight & Normal & Overweight & Obese & Underweight & Normal & Overweight & Obese \\
\hline \multirow{11}{*}{ Recent } & $18-29$ & 4.9 & 54.1 & 27.8 & 13.2 & 11.8 & 61.2 & 15.9 & 11.1 \\
\hline & $30-39$ & 0.8 & 33.2 & 41.7 & 24.3 & 5.1 & 50.9 & 23.9 & 20.1 \\
\hline & $40-49$ & 1.1 & 24.4 & 41.2 & 33.3 & 2.2 & 40.7 & 28.4 & 28.7 \\
\hline & $50-59$ & 0.6 & 21.3 & 39.5 & 38.6 & 1.1 & 27.3 & 35.3 & 36.6 \\
\hline & $60-69$ & 0.6 & 16.4 & 43.0 & 40.1 & 0.8 & 21.2 & 36.4 & 41.6 \\
\hline & $70<$ & 0.6 & 21.4 & 46.1 & 31.9 & 0.9 & 23.7 & 38.2 & 37.2 \\
\hline & $18-34$ & 3.6 & 47.7 & 32.5 & 16.2 & 10.0 & 58.4 & 17.8 & 13.8 \\
\hline & $35-54$ & & & & & 2.3 & 39.1 & 29.7 & 29.0 \\
\hline & $35-59$ & 0.7 & 24.0 & 40.6 & 34.7 & 1.9 & 35.4 & 31.4 & 31.3 \\
\hline & $55<$ & & & & & 0.9 & 23.2 & 36.9 & 39.0 \\
\hline & $60<$ & 0.6 & 18.5 & 44.3 & 36.7 & & & & \\
\hline \multirow{6}{*}{ Former } & $18-34$ & 5.7 & 57.1 & 32.2 & 4.9 & 18.4 & 55.5 & 19.8 & 6.3 \\
\hline & $35-54$ & & & & & 5.1 & 42.0 & 35.0 & 17.6 \\
\hline & $35-59$ & 3.1 & 34.0 & 48.2 & 14.2 & & & & \\
\hline & $55-74$ & & & & & 2.1 & 23.1 & 41.8 & 32.1 \\
\hline & $60-74$ & 3.4 & 29.8 & 49.3 & 17.5 & & & & \\
\hline & $75<$ & 5.9 & 35.9 & 45.9 & 12.4 & 4.0 & 33.0 & 40.0 & 22.9 \\
\hline
\end{tabular}

Distribution of individuals in the different BMI categories regarding age periods and decades (in percent). Comparison between recent and former data [3]. 
Table 2 Means of BMI

\begin{tabular}{|c|c|c|c|}
\hline & \multirow[b]{2}{*}{$\begin{array}{c}\text { Age } \\
\text { [year] }\end{array}$} & \multirow{2}{*}{ 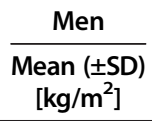 } & \multirow{2}{*}{$\begin{array}{c}\text { Women } \\
\text { Mean ( } \pm \text { SD) } \\
{\left[\mathrm{kg} / \mathrm{m}^{2}\right]}\end{array}$} \\
\hline & & & \\
\hline \multirow{11}{*}{ Recent } & $18-29$ & $24.7( \pm 4.8)$ & $23.23( \pm 5.2)$ \\
\hline & $30-39$ & $27.3( \pm 4.8)$ & $25.49( \pm 5.8)$ \\
\hline & $40-49$ & $28.5( \pm 5.4)$ & $27.17( \pm 5.9)$ \\
\hline & $50-59$ & $29.1( \pm 5.3)$ & $28.65( \pm 5.7)$ \\
\hline & $60-69$ & $29.3( \pm 4.9)$ & $29.34( \pm 5.4)$ \\
\hline & $70<$ & $28.4( \pm 4.5)$ & $28.64( \pm 5.2)$ \\
\hline & $18-34$ & $25.5( \pm 4.9)$ & $23.86( \pm 5.5)$ \\
\hline & $35-59$ & $28.6( \pm 5.3)$ & \\
\hline & $35-54$ & & $27.24( \pm 5.9)$ \\
\hline & $55<$ & & $28.97( \pm 5.4)$ \\
\hline & $60<$ & $28.9( \pm 4.7)$ & \\
\hline \multirow{6}{*}{ Former } & $18-34$ & 24.2 & 23.3 \\
\hline & $35-54$ & & 26.0 \\
\hline & $35-59$ & 26.3 & \\
\hline & $55-74$ & & 28.1 \\
\hline & $60-74$ & 26.7 & \\
\hline & $75<$ & 25.8 & 27.0 \\
\hline
\end{tabular}

Distribution in different age periods. Comparison between recent and former data [3].

Table 4 shows the distribution of BMI and waist circumference categories regarding different levels of education. Fewer people with higher education were represented in the obese category. Men with a higher degree had the highest proportion among the overweight BMI group and also higher in the normal then in obese group, while females had the lowest record among the obese and the highest in the normal range. Similar results were found according to waist circumference. In the categories of obesity (regarding BMI and waist circumference) there were inverse relations between odds ratios and degrees of education.
In both genders, these differences were mostly statistically significant when comparing primary and other educational levels.

The prevalence data for obesity was the highest in the villages (35.4\%), the lowest in Budapest (28.9\%). Overweight was "only" (33.9\%) in the villages, the highest in Budapest (37.1\%) and 35.8\% in the cities. Persons within normal BMI range were only $31.8 \%$ in Budapest. They represented the $32.5 \%$ of other urban and $28.6 \%$ of rural population.

As presented in Table 5 the incidence of registered metabolic morbidities (hypertension and diabetes) was different regarding type of domiciles, showing an inverse correlation with the number of inhabitants. The lowest was in Budapest and the highest in rural settings. These morbidities were also significantly correlated with levels of education and categories of BMI, with strong relation to the increasing age.

\section{Discussion \\ Main findings}

Comparing the data of a quarter century ago, the BMI has become higher in all age categories and the distribution of the population also tended toward being overweight, moreover obese, resulting a 2-4-fold increase in the percentage of incidence in some age groups. This shift has been more prominent among males. Their BMIs have been higher from the middle decades, while earlier women used to have larger surplus, which means rearrangement between categories, a shift from being overweight to becoming obese.

Significant differences were found between the educational level and BMI categories. Although there were fewer obese persons among the subjects with higher education, being overweight was common, while women with a higher degree were less obese.

Registered metabolic morbidities were strongly correlated with BMI and both were inversely related to the level of urbanization.

Table 3 Waist circumference

\begin{tabular}{|c|c|c|c|c|c|c|}
\hline \multirow[b]{2}{*}{ Age [y] } & \multicolumn{3}{|c|}{ Men } & \multicolumn{3}{|c|}{ Women } \\
\hline & $\begin{array}{l}\text { Normal } \\
<94 \mathrm{~cm}\end{array}$ & $\begin{array}{c}\text { Risky } \\
94-102 \mathrm{~cm}\end{array}$ & $\begin{array}{l}\text { Abdominal obesity } \\
\qquad 102 \mathrm{~cm}<\end{array}$ & $\begin{array}{l}\text { Normal } \\
<80 \mathrm{~cm}\end{array}$ & $\begin{array}{c}\text { Risky } \\
80-88 \mathrm{~cm}\end{array}$ & $\begin{array}{l}\text { Abdominal obesity } \\
\qquad 88 \mathrm{~cm}<\end{array}$ \\
\hline $18-29$ & 72.6 & 14.1 & 13.3 & 54.6 & 19.5 & 25.9 \\
\hline $30-39$ & 50.5 & 23.2 & 26.3 & 37.3 & 21.0 & 41.7 \\
\hline $40-49$ & 38.9 & 25.1 & 36.0 & 25.9 & 19.9 & 54.2 \\
\hline $50-59$ & 31.3 & 25.6 & 43.2 & 14.8 & 16.4 & 68.8 \\
\hline $60-69$ & 26.0 & 25.5 & 48.5 & 9.3 & 13.9 & 76.8 \\
\hline $70<$ & 29.2 & 28.2 & 42.6 & 12.1 & 13.0 & 75.0 \\
\hline
\end{tabular}

Distribution of men and women in established categories of abdominal obesity (normal, cardiovascular risk and abdominal obesity) in percent. 
Table 4 Educational level, BMI and waist circumference

\begin{tabular}{|c|c|c|c|c|c|c|c|}
\hline \multirow{3}{*}{ Category } & \multicolumn{7}{|c|}{ Men [\%] } \\
\hline & \multicolumn{4}{|c|}{ BMI $\left[\mathrm{kg} / \mathrm{m}^{2}\right]$} & \multicolumn{3}{|c|}{ Waist circumference $[\mathrm{cm}]$} \\
\hline & Underweight & Normal & Overweight & Obese & Normal & Risky & Abdominal obesity \\
\hline \multicolumn{8}{|l|}{ Education } \\
\hline Under & 2.0 & 30.1 & 39.7 & 28.3 & 39.5 & 23.2 & 37.3 \\
\hline OR (95\% Cl) & $1.04[0.54-2.02]$ & $1.12[0.91-1.37]$ & 1.19 [0.99-1.44] & $\mathbf{0 . 7 4} *[0.61-0.91]$ & $1.06[0.88-1.28]$ & $0.99[0.80-1.24]$ & $0.94[0.78-1.14]$ \\
\hline Primary & 1.9 & 27.8 & 35.7 & 34.7 & 38.1 & 23.2 & 38.8 \\
\hline OR $(95 \% \mathrm{Cl})$ & 1.00 & 1.00 & 1.00 & 1.00 & 1.00 & 1.00 & 1.00 \\
\hline Secondary & 1.1 & 24.9 & 40.7 & 33.3 & 37.9 & 23.8 & 38.4 \\
\hline OR $(95 \% \mathrm{Cl})$ & $\mathbf{0 . 5 8} *[0.42-0.79]$ & $\mathbf{0 . 8 6 *}[0.79-0.94]$ & $\mathbf{1 . 2 4} *[1.15-1.34]$ & $\mathbf{0 . 9 4} *[0.87-1.02]$ & $\mathbf{0 . 9 9} *[0.92-1.07]$ & $1.03 *[0.94-1.13]$ & $\mathbf{0 . 9 9 *}[0.91-1.07]$ \\
\hline High & 0.6 & 28.0 & 45.3 & 26.1 & 40.6 & 25.7 & 33.8 \\
\hline \multirow[t]{2}{*}{ OR $(95 \% \mathrm{Cl})$} & $0.31[0.17-0.55]$ & $1.01 *[0.90-1.14]$ & $\mathbf{1 . 5 0 *}[1.35-1.67]$ & $\mathbf{0 . 6 6 *}[0.59-0.74]$ & $\mathbf{1 . 1 1 *}[0.99-1.23]$ & $\mathbf{1 . 1 5 *}[1.02-1.29]$ & $\mathbf{0 . 8 1 *}[0.72-0.89]$ \\
\hline & \multicolumn{7}{|c|}{ Women [\%] } \\
\hline Under & 3.1 & 26.1 & 29.8 & 41.0 & 17.0 & 12.4 & 70.6 \\
\hline OR (95\% Cl) & $\mathbf{1 . 1 5 *}[0.81-1.65]$ & $1.01 *[0.88-1.16]$ & $\mathbf{0 . 8 7} *[0.76-0.99]$ & $\mathbf{1 . 1 1} *[0.98-1.26]$ & $1.09 *[0.93-1.29]$ & $\mathbf{0 . 8 7 *}[0.73-1.05]$ & $1.02 *[0.89-1.16]$ \\
\hline Primary & 2.7 & 25.9 & 32.8 & 38.5 & 15.7 & 14.0 & 70.3 \\
\hline OR (95\% Cl) & 1.00 & 1.00 & 1.00 & 1.00 & 1.00 & 1.00 & 1.00 \\
\hline Secondary & 3.1 & 37.1 & 31.6 & 28.1 & 24.3 & 18.4 & 57.3 \\
\hline OR (95\% Cl) & $1.16[0.96-1.40]$ & $\mathbf{1 . 6 8 *}[1.57-1.80]$ & $0.95[0.88-1.01]$ & $\mathbf{0 . 6 3} *[0.59-0.67]$ & $\mathbf{1 . 7 3}^{*}[1.59-1.88]$ & $\mathbf{1 . 3 8} *[1.27-1.52]$ & $\mathbf{0 . 5 7 *}[0.53-0.61]$ \\
\hline High & 2.7 & 50.2 & 26.8 & 20.3 & 32.3 & 20.3 & 47.5 \\
\hline OR (95\% Cl) & $1.01[0.78-1.31]$ & $\mathbf{2 . 8 8}^{*}[2.63-3.15]$ & $\mathbf{0 . 7 5}$ [0.68-0.82] & $\mathbf{0 . 4 1} *[0.37-0.45]$ & $\mathbf{2 . 5 5 ^ { * }}[2.31-2.82]$ & $\mathbf{1 . 5 6 *}[1.39-1.75]$ & $\mathbf{0 . 3 8} *[0.35-0.42]$ \\
\hline
\end{tabular}

Distribution of participants according to different levels of education, different groups of BMI, and waist circumference [in percent]. Odds ratios (OR) and confidence intervals $[95 \% \mathrm{Cl}]$ with reference to primary level of education. Significance is marked with bold and *.

\section{Comparison with previous research}

Previous Hungarian studies used different methods and other age categories for the selection of participants; therefore it was often difficult to make proper comparison. Most of these studies had a much lower number of participants $[4,6-10]$. At the time of the first nationwide survey 25 years ago, Hungary still had 10.6 million inhabitants. Individuals included in the study represented $0.16 \%$ of the whole population [3]. Currently, with the number of the population decreasing, our study has achieved a $0.53 \%$ participation rate in the age-cohort over 18 years. This ratio is much higher than that of the

Table 5 Morbidities

\begin{tabular}{|c|c|c|c|c|c|c|c|c|c|c|}
\hline \multirow[t]{2}{*}{ Category } & \multicolumn{5}{|c|}{ Women } & \multicolumn{5}{|c|}{ Men } \\
\hline & OR & Std. error & $P>z$ & & & OR & Std. error & $P>z$ & & \\
\hline Cities & 1.278 & 0.093 & 0.001 & 1.107 & 1.473 & 1.107 & 0.088 & 0.201 & 0.947 & 1.295 \\
\hline Villages & 1.071 & 0.080 & 0.356 & 0.925 & 1.239 & 1.052 & 0.086 & 0.532 & 0.895 & 1.237 \\
\hline Ref.: primary & 1.00 & & & & & 1.00 & & & & \\
\hline Under & 1.018 & 0.074 & 0.810 & 0.881 & 1.174 & 1.075 & 0.110 & 0.482 & 0.878 & 1.315 \\
\hline Secondary & 0.471 & 0.017 & $<0.001$ & 0.438 & 0.505 & 0.629 & 0.027 & $<0.001$ & 0.578 & 0.685 \\
\hline High & 0.308 & 0.015 & $<0.001$ & 0.279 & 0.340 & 0.620 & 0.035 & $<0.001$ & 0.554 & 0.694 \\
\hline Ref.: normal & 1.00 & & & & & 1.00 & & & & \\
\hline Underweight & 5.354 & 0.216 & $<0.001$ & 4.946 & 5.795 & 5.354 & 0.264 & $<0.001$ & 4.859 & 5.899 \\
\hline Overweight & 2.685 & 0.100 & $<0.001$ & 2.496 & 2.888 & 2.470 & 0.110 & $<0.001$ & 2.263 & 2.696 \\
\hline Obese & 0.372 & 0.041 & $<0.001$ & 0.298 & 0.461 & 0.623 & 0.107 & 0.006 & 0.443 & 0.874 \\
\hline
\end{tabular}

Odds ratios (OR), level of significance and $95 \%$ confidence intervals $(\mathrm{Cl})$ for metabolic diseases (hypertension or/and diabetes) by different type of domiciles, by different levels of education and BMI categories. Significance is marked with bold. 
similar surveys in other countries. Data regarding education and waist circumference have not been compared or analyzed before. Another problem emerged, because the distribution of data within different age-cohort regarding gender was not identical. Earlier, the official retirement age was 55 years for women and 60 years for men. We tried to present our data considering the grouping of this survey as well. Previously, $20 \mathrm{~kg} / \mathrm{m}^{2}$ was used as a lower threshold of normal BMI-group, but the WHO has recently introduced the limit of $18.5 \mathrm{~kg} / \mathrm{m}^{2}$.

Comparing our data to that of neighboring countries, these figures are higher although they were given almost within the same range in the WHO database $[1,11]$. In Austria, in the Western neighbor country, in the selfreported data from 5 surveys was compared, analyzing the decade-long trend in the incidence of obesity. In 2007, the prevalence of overweight was higher among men than women $(46.3 \%$ vs. $31.2 \%)$. There was a clear east-west gradient for obesity in both sexes; the highest figures were found in Eastern Austria: 18.1\% for women and $16.1 \%$ for men [2]. There was also a higher prevalence of obesity in the former Soviet-bloc (socialist) countries. It could be explained by many similar social and economic reasons as well $[1,2]$.

Although Hungary is situated mainly in lower terrains (the highest mountain is $1014 \mathrm{~m}$ above sea level) there were only small differences $(100-300 \mathrm{~m})$ regarding altitudes between geographic locations of GPs. It is not surprising that data were mainly similar without such differences as presented in a study from the US, with lower registered BMI of persons living in the mountains [12]. Findings were similar regarding to the higher incidence of metabolic morbidities among rural population. Urbanization and obesity prevalence exhibited an inverse relationship.

There was no more comparison to available data of other countries worldwide, while almost all of them have to face to the "obesity pandemic" $[1,13]$.

People living in smaller settings may have many disadvantages regarding access to healthcare delivery. This reason combined with their lifestyle, which is often not appropriate could be the reason for higher incidence rate of metabolic morbidities and overweight/obesity.

Requirement regarding representativeness of educational level was properly fulfilled. Comparing the population at large in Hungary and that of the study, undereducated were both $5 \%$, primary and secondary schools were completed by ( $27 \%$ vs. $33 \%)$ and $(51 \%$ vs. $46 \%)$ and (14\% vs. $15 \%)$ had higher educational degree [5].

\section{Limitations and strengths}

The participants of this nationwide survey were mainly primary care patients and less from community settings. Without appropriate registration, the real ratio is unknown. It might be the reason why the peak of the age tree of participants was almost 10 years higher than that of the population at large. Patients with cardiovascular morbidities might have been overrepresented, although prevalence of the 2 registered metabolic diseases (hypertension and diabetes) in the older generation of men was closer to the data of national morbidity register (below 35 y: $13.5 \%$ vs $18 \%$, between $35-65$ y: $71 \%$ vs $76 \%$; above 65 y: $79 \%$ vs $82 \%$ ) $[5,14]$. There were similar data by female as well. The very simply process of randomization (the first persons), the high number of participants and data presentations according to smaller age groups (life-decades), and to waist circumference, which were not measured previously, could counterbalance this possible bias.

Although anthropometric data were measured by the medical staff, individual inaccuracy could also be encountered, but it could be balanced during under- and over recording.

\section{Conclusions}

Primary care settings can be a proper place to register and follow up anthropometric parameters and family physicians should be motivated to perform it continuously. Early medical intervention or even advices can help in the prevention of obesity. Proper under- and postgraduate education and use of updated guidelines could be a professional help in daily practices of family physicians, not only in Hungary $[15,16]$.

Beside the involvement of health workers, much more governmental support, population awareness are needed and clear health policy recommendations should be outlined.

\section{Competing interests}

The authors declare that they have no competing interests.

The study has been financed from departmental resources only.

The study design was approved by the National Ethical Committee of Scientific Research, Budapest (ETT TUKEB-20928).

A limited number of participating GPs were given a symbolic compensation for collecting data.

\section{Authors' contributions}

IR and PT were involved in developing the concept, implementation of the study, presentation of data, writing and editing the manuscript. JSz, CsM, GI, were involved in the organization, collection and processing of data, ÉA and ZJ also in the structuring of the manuscript. UT and JS analyzed and presented the data. All the authors read and approved the final manuscript

\section{Acknowledgement}

We are very grateful to the family physicians and practice nurses who contributed in the survey. Thanks to Ms. Judit Rusznyák for data processing and to Mrs. Juszti Jánossy-Nagy for language corrections.

\section{Author details}

${ }^{1}$ Department of Family and Occupational Medicine, Faculty of Public Health, University of Debrecen, Móricz Zs. krt.22, 4032 Debrecen, Hungary. ${ }^{2}$ Division of Biostatistics and Epidemiology, Department of Preventive Medicine, Faculty of Public Health, University of Debrecen, Debrecen, Hungary. ${ }^{3}$ Department of Family Medicine, Faculty of Medicine, Semmelweis University, Budapest, Hungary. ${ }^{4}$ Irinyi Primary Health Care Center, Kecskemét, Hungary. 


\section{References}

1. WHO Global Health Observatory Data repository. http://apps.who.int/gho/ data/node.main.A897?lang=en (accessed 20th August 2013).

2. Großschädl F, Stronegger WJ: Regional trends in obesity and overweight among Austrian adults between 1973 and 2007. Wien Klin Wochschr 2012, 124:363-369.

3. Biró G: The First Hungarian Representative Nutrition Survey (1985-1988). Budapest: National Institute of Food Hygiene and Nutrition; 1992.

4. Zajkás G, Biró G: Some date on the prevalence of obesity in Hungarian adult population between 1985-88 and 1992-94. Z Ernährungswiss 1998, 37:S1134-S1135.

5. Central Institute of Statistics: Hungarian Central Statistical Office, Population census, 2011. www.ksh.hu/nepszamlalas/tablak_teruleti_00 (accessed 29th July 2013).

6. Balogh S, Kékes E, Császár A: Estimation of cardiovascular risk factors within primary care practices. The CORPRAX study. Medicus Universalis 2004, 2:3-7. in Hungarian.

7. Martos É, Kovács VA, Bakacs M, Kaposvári C, Lugasi A: Hungarian diet and nutritional survey-the OTAP 2009 study. I. Nutritional status of the Hungarian population. Orv Hetil 2012, 153:1023-1030. in Hungarian.

8. Martos É, Bakacs M, Kaposvári C: Prevalence of obesity in Hungary in 2009. Obes Rev 2011, 12:S1-S108.

9. Bényi M, Kéki Z, Hangay I, Kókai Z: Obesity related increase in diseases in Hungary studied by the health interview survey 2009. Orv Hetil 2012, 153:768-775.

10. Halmy L, Simonyi G, Csatai T, Paksy A: Hungarian policemen study on the prevalence of obesity. Int J Obes 2003, 227:S1-S132.

11. Petek D, Kern N, Kovač-Blaž M, Kersnik J: Efficiency of community based intervention programme on keeping lowered weight. Zdrav Var (Slovenian J Public Health) 2011, 50:160-168.

12. Voss JD, Masuoka P, Webber BJ, Scher Al, Atkinson RL: Association of elevation, urbanization and ambient temperature with obesity prevalence in the United States. Int J Obes (Lond) 2013, 37:1407-1412.

13. Walpole SC, Prieto-Merino D, Edwards P, Cleland J, Stevens G, Roberts I: The weight of nations: an estimation of adult human biomass. BMC Public Health 2012, 12:439.

14. Central Statistical Office: Hungarian Central Statistical Office, Dissemination database. http://statinfo.ksh.hu/Statinfo/haViewer.jsp?wcfc55ab638=x.

15. Rurik I, Torzsa P, llyés I, Szigethy E, Halmy E, Iski G, Kolozsvári LR, Mester L, Móczár C, Rinfel J, Nagy L, Kalabay L: Primary care obesity management in Hungary: evaluation of the knowledge, practice and attitudes of family physicians. BMC Fam Pract 2013, 14(1):156

16. Jensen MD, Ryan DH, Apovian CM, Ard JD, Comuzzie AG, Donato KA, Hu FB, Hubbard VS, Jakicic JM, Kushner RF, Loria CM, Millen BE, Nonas CA, Pi-Sunyer FX, Stevens J, Stevens VJ, Wadden TA, Wolfe BM, Yanovski SZ, 2013 AHA/ACC/TOS: Guideline for the management of overweight and obesity in adults: a report of the American college of cardiology/ American heart association task force on practice guidelines and the obesity society. Circulation 2013, Epub ahead of print.

\section{doi:10.1186/1471-2458-14-798}

Cite this article as: Rurik et al: A public health threat in Hungary: obesity, 2013. BMC Public Health 2014 14:798.

\section{Submit your next manuscript to BioMed Central and take full advantage of:}

- Convenient online submission

- Thorough peer review

- No space constraints or color figure charges

- Immediate publication on acceptance

- Inclusion in PubMed, CAS, Scopus and Google Scholar

- Research which is freely available for redistribution 